ISSN 2447-9071

doi https://doi.org/10.36414/rbmc.v7i17.92

\section{Anais do XVII Congresso Brasileiro de Biomedicina e V Congresso Internacional de Biomedicina}

\section{A exposição de camundongos machos à rosuvastatina desde a pré- puberdade atrasa a instalação da puberdade e aumenta a perda pós- implantação}

Ana Beatriz Göedert, Julia Schubert Sengl de Souza, Gabriel Adan Araújo Leite

Área: Toxicologia

Instituição de Origem: Universidade Federal de Santa Catarina - UFSC

INTRODUÇÃO: O uso das estatinas tem sido potencializado atualmente devido à maior incidência de obesidade em várias faixas etárias, gerando predisposição para disfunções metabólicas como as dislipidemias. OBJETIVO: Investigar as consequências reprodutivas da exposição de camundongos Swiss machos à rosuvastatina da pré-puberdade até a maturidade sexual. MÉTODOS: Os três grupos experimentais ( $n=10 / g r u p o$ ) receberam diariamente do dia pós natal (DPN) 23 ao 80 , salina $0,9 \%, 1,5$ ou $5,5 \mathrm{mg} / \mathrm{kg}$ de rosuvastatina por via oral. Após acasalamento natural com fêmeas não-tratadas, avaliaram-se as taxas de fertilidade e os parâmetros fetais. Foram analisados o peso dos órgãos reprodutores e vitais, evolução do peso e instalação da puberdade. RESULTADOS: Em ambas as doses, constatou-se retardo na instalação da puberdade e peso corpóreo maior nesta fase. $\mathrm{O}$ grupo exposto à menor dose apresentou peso da glândula seminal vazia diminuído. Além disso, nos dois grupos tratados ocorreu uma tendência de aumento da taxa de perda pós- implantação. Os demais parâmetros não se mostraram alterados. CONCLUSÃO: O estudo aponta uma possível redução dos níveis de andrógenos, visto que a rosuvastatina atrasa a instalação da puberdade e diminui o peso da glândula seminal vazia, ambos fatores andrógeno-dependentes. Ademais, sugere-se que a exposição à estatina prejudique o desenvolvimento embrionário, mediado por fator paterno, conforme indicado pelo aumento da perda pós-implantação.

DESCRITORES: Camundongos; Rosuvastatina; Reprodução Masculina; Toxicidade. 
ISSN 2447-9071

doi https://doi.org/10.36414/rbmc.v7i17.92

\section{Anais do XVII Congresso Brasileiro de Biomedicina e V Congresso Internacional de Biomedicina}

\section{Ações de Promoção da Saúde nas Mídias Sociais e Uso das Tecnologias Digitais}

Mayara Nerina Fortes Arthur, Jéssica Beatriz Ferreira, Juliana Silva de Lima, Vânia Nakauth Azevedo, Karla Tereza Silva Ribeiro

Área: Saúde Pública

Instituição de Origem: Universidade Federal do Pará. Instituto de Ciências Biológicas.

INTRODUÇÃO: As ações que promovam educação em saúde são atribuições dos profissionais que atuam na área da saúde, como os Biomédicos. E o uso das Tecnologias Digitais de Informação e Comunicação (TDIC's), aliadas as mídias sociais (Facebook; Instagram, Edublog etc.), auxiliam na disseminação de informações à sociedade relacionadas com a prevenção dos agravos e promoção da saúde. OBJETIVO: Considerando a importância do processo de integração das tecnologias e mídias digitais ao ensino superior, o objetivo deste trabalho foi compartilhar as habilidades criativas dos discentes do Curso de Biomedicina na elaboração de produtos digitais, disponibilizados no Edublog Educação, Saúde e Meio Ambiente (http://saudeambientalufpa.blogspot.com/), com finalidade de socializar o conhecimento adquirido na graduação junto à comunidade, e a adoção de novos hábitos e condutas de saúde. MÉTODOS: Na etapa inicial os alunos são organizados em equipes, e são disponibilizadas lista de referências, artigos científicos e links de busca eletrônica referente aos temas complementares ao conteúdo ministrado. Na etapa seguinte, os alunos são orientados na elaboração de um resumo (pode ser expandido) e pôster (infográfico) a ser disponibilizado no blog "Educação, Saúde e Meio Ambiente". No início este blog foi criado especialmente para uma disciplina ministrada no $6^{\circ}$ período do curso de Biomedicina da UFPA. Atualmente faz parte de projetos de extensão e integra alunos de outros cursos, como do curso de Ciências Biológicas. RESULTADOS: Na consulta atual do material educativo disponibilizado no Edublog "Saúde e Ambiente Amazônico"foi possível observar 48.835 (27/11/2020) visualizações procedentes de diferentes países, com concentração no Brasil. E apesar das dificuldades de divulgação, as informações estatísticas do blog revelam uma boa aceitação do público. Isso mostra que os temas que envolvem saúde e meio ambiente, promoção da saúde e prevenção de agravos/doenças, são de interesse do público que visita o nosso blog. CONCLUSÃO: O Edublog tem contribuído na formação dos alunos como multiplicadores do conhecimento adquirido na graduação, usando as TDIC's e redes sociais, para divulgar diferentes temas relacionados com a saúde pública e meio ambiente, incluindo a pandemia do coronavírus.

DESCRITORES: Camundongos; Rosuvastatina; Reprodução Masculina; Toxicidade. 
ISSN 2447-9071

doi https://doi.org/10.36414/rbmc.v7i17.92

\section{Anais do XVII Congresso Brasileiro de Biomedicina e V Congresso Internacional de Biomedicina}

\section{Alterações bioquímicas, hematológicas e reprodutivas, induzidas pelo Diclofenaco de Sódio e Celecoxibe em ratos Wistar}

Gabriela Neves Masalskas, Karoline Nunes Magalhães Pereira Paiva, Renata Santos de Oliveira, Ariádna Deyse Gonçalves Souza, Ana Rosa Crisci

Área: Bioquímica, hematologia, histologia.

Instituição de Origem: Centro Universitário Barão de Mauá.

INTRODUÇÃO: Os anti-inflamatórios não esteroides (AINEs) fazem parte de uma classe de fármacos variáveis e são frequentemente utilizados no Brasil, com função anti-inflamatória, analgésica e antipirética, inibindo enzimas chamadas ciclooxigenases (COX). OBJETIVO: Avaliar alterações induzidas por dois anti- inflamatórios não esteroides, de acordo com a sua capacidade de inibir as enzimas ciclooxigenases (COX-1 e COX-2) e facilidade de aquisição. MÉTODOS: Foram utilizados 24 ratos machos saudáveis da linhagem Wistar, sendo divididos em 3 grupos com 8 animais cada e analisadas: massa corporal, dosagens de ureia, creatinina, transaminases (ALT e AST), hemograma e histopatologia, seguindo as normas do comitê de Ética CEPan sob o protocolo número 364/2019. RESULTADOS: Houve alterações no hemograma, especialmente com redução no valor do hematócrito no grupo submetido ao diclofenaco de sódio. Perda de massa corporal, queda nos valores de ureia, degeneração hepatocelular, córtex renal com áreas hemorrágicas e inflamatórias, e alteração na arquitetura da mucosa gástrica foram observados neste mesmo grupo. Ambos os grupos de animais submetidos aos anti-inflamatórios apresentaram leucocitose. Não foi observado esterilidade nos grupos. CONCLUSÃO: O Diclofenaco de sódio, medicamento de fácil aquisição de compra é o que causa maior dano ao organismo em relação ao Celecoxibe, que tem sua compra condicionada à retenção de receita médica.

DESCRITORES: Diclofenaco; Celecoxibe; AINE. 
ISSN 2447-9071

doi https://doi.org/10.36414/rbmc.v7i17.92

\section{Anais do XVII Congresso Brasileiro de Biomedicina e V Congresso Internacional de Biomedicina}

\section{Análise das medidas de preenção contra SARS-CoV-2 durante período de isolamento em Itumbiara-GO}

Wellington Pereira de Oliveira Júnior, Isadora Brunielly Silva, Lorrane Rodrigues Mendes, Lorrany Luanda Félix, Any Gabriely Mendes, Alice Gomes Gouveia, Ayanda Ferreira Nascimento Lima, Guilherme Soares Buzzo

Área: Saúde Pública

Instituição de Origem: Una Itumbiara.

INTRODUÇÃO: Em dezembro de 2019 uma mutação do SARS-CoV surgiu na China espalhando rapidamente pelo mundo, declarando pandemia apóspoucos meses. Por ser um vírus novo que não se conhecia, foram tomadas medidas para evitar sua proliferação. OBJETIVO: Analisar medidas tomadas pela população e estabelecimentos em ItumbiaraGO. MÉTODOS: Foram utilizados formulários via redes sociais para a população, funcionários e donos de estabelecimentos, durante o mês de maio. RESULTADOS: Foram analisadas 132 respostas da população. Destas, 6,9\% não saiam nenhuma vez por semana, $29,8 \%$ saiam todo dia, $61,1 \%$ utilizavam todas as medidas de segurança, $4,6 \%$ tiveram contato com doentes, $49,6 \%$ disseram que estabelecimentos poderiam melhorar as medidas de prevenção, e 49,6\% acredita que as medidas não estão sendo satisfatórias. De 24 estabelecimentos, 45,5\% instalaram barreiras entre clientes e funcionários, 58,3\% limpavam as maçanetas mais de 3 vezes ao dia, $68,6 \%$ utilizavam álcool $70 \%, 66,7 \%$ limpavam todos os produtos, $69,4 \%$ haviam limite controlado de pessoas dentro do estabelecimento, $97,2 \%$ exigiam uso de máscaras para entrar no local e 91,7\% disponibilizavam álcool em gel para funcionários e clientes. CONCLUSÃO: Os estudos apontam que houve descuido no cumprimento das medidas contra a dispersão do novo coronavírus. Acredita- se que foi devido a análise ter sido realizada na fase inicial do isolamento, período em que a população estava se adaptando à nova realidade.

DESCRITORES: Coronavírus; Isolamento Social; Profilaxia. 
ISSN 2447-9071

doi https://doi.org/10.36414/rbmc.v7i17.92

\section{Anais do XVII Congresso Brasileiro de Biomedicina e V Congresso Internacional de Biomedicina}

\section{Análise morfométrica da tela submucosa do duodeno de Rattus norvegicus submetidos à infecção crônica por Toxoplasma gondii e tratados por Echinacea purpúrea}

Mariana Buranelo, Claudia Nara de Almeida Lino, Maria José Pastre, Aline Rosa Trevizan, Debora de Mello Gonçales Sant'Ana

Área: Outras da saúde

Instituição de Origem: Universidade Estadual de Maringá (UEM)

INTRODUÇÃO: A transmissão do Toxoplasma gondii ocorre principalmente por via oral e pode provocar alterações teciduais no intestino. O extrato da Echinacea purpurea é considerado imunoestimulante e anti-inflamatório. OBJETIVOS: Analisar a morfometria da túnica submucosa do duodeno de ratos submetidos a infecção crônica por T. gondii e tratados com Echinacea Purpurea. MÉTODOS: O experimento foi aprovado pelo CEUA-

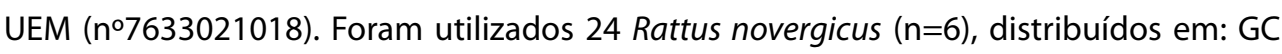
(Grupo controle), GI-NT (Grupo infectado não tratado), GC-EP100 (Grupo controle tratado) e GI-EP100 (Grupo infectado tratado). Os ratos dos grupos GC-EP100 e GI-EP100 foram tratados com $100 \mathrm{mg} / \mathrm{kg}$ de Echinacea purpurea via oral por 28 dias antes e depois da data da inoculação. Os grupos infectados foram inoculados com 500 oocistos de T. gondii (cepa $\mathrm{RH}$ ) via oral. Foi realizada a eutanásia dos ratos, os duodenos foram submetidos a rotina histológica e corados por Hematoxilina e Eosina. A morfometria da tela submucosa foi realizada em 16 campos microscópicos por animal na objetiva de 10x no software Image Pro Plus. Os resultados foram expressos em média \pm desvio padrão. RESULTADOS: Não houve diferença significativa na espessura da tela submucosa do GC $(50,81 \pm 3,87$ $\mu \mathrm{m}), \mathrm{GC}-\mathrm{EP} 100(52,68 \pm 3,67 \mu \mathrm{m})$, GI-NT $(50,96 \pm 5,29 \mu \mathrm{m})$ e GI-EP100 $(52,42 \pm 3,25 \mu \mathrm{m})$. CONCLUSÃO: A infecção crônica pelo T. gondii e o tratamento com Echinacea purpurea não alteram a espessura da tela submucosa do duodeno de ratos.

DESCRITORES:Duodeno; Echinacea purpurea;Tela submucosa;Tratamento;Toxoplasmose. 
ISSN 2447-9071

doi https://doi.org/10.36414/rbmc.v7i17.92

\section{Anais do XVII Congresso Brasileiro de Biomedicina e V Congresso Internacional de Biomedicina}

\section{Aspectos hematológicos, bioquímicos e reprodutivos do citrato de sildenafil e do tadalafil administrados em ratos wistar}

Ellen do Prado Mestriner, Lívia Pignata de Andrade, Cinthia Rivoiro Fernandes, Ana Rosa Crisci

Área: Análises Clínicas

Instituição de Origem: Centro Universitário Barão de Mauá - SP

INTRODUÇÃO: O início dos anos 2000 revolucionou a medicina sexual com a introdução dos inibidores de fosfodiesterase tipo 5 , usados para disfunção erétil, como o Citrato de Sildenafil e Tadalafil. OBJETIVO: Investigar os efeitos adversos do Citrato de Sildenafil e do Tadalafil. MÉTODOS: Foram utilizados 24 ratos machos da linhagem Wistar, separados ao acaso em três grupos: Controle, Citrato de Sildenafil e Tadalafil. RESULTADOS: 0 grupo Citrato de Sildenafil apresentou uma diminuição no AST $(p=0,003)$ e perda da massa corporal ( $p=0,0004$.); o grupo Tadalafil apresentou um aumento na hemoglobina e contagem total de hemácias; na histopatologia do fígado, ambos os grupos apresentaram infiltrado leucocitário e degeneração hidrópica, os rins não apresentaram resultados significativos; já os túbulos seminíferos apresentaram-se diminuídos e com alterações nas células da linhagem espermatogênica; ambos os grupos da droga apresentaram espermatozóides com motilidade baixa e morfologia anormal, sendo o Citrato de Sildenafil que apresentou uma intensa diminuição no vigor ( $p=0,0001)$. CONCLUSÃO: a partir dos resultados conclui-se que: a droga em que mais apresentou alterações foi o Citrato de Sildenafil.

DESCRITORES: Citrato de Sildenafil; Tadalafil. 
ISSN 2447-9071

doi https://doi.org/10.36414/rbmc.v7i17.92

\section{Anais do XVII Congresso Brasileiro de Biomedicina e V Congresso Internacional de Biomedicina}

\section{Ausência de sazonalidade em casos de diarreia em um município do sudoeste goiano}

Henrique Polizelli Pinto Neto, Melissa Carvalho Martins de Abreu, Camila Botelho Miguel, Wellington Francisco Rodrigues

Área: Saúde Pública

Instituição de Origem: Centro Universitário de Mineiros - UNIFIMES; Universidade Federal do Triângulo Mineiro - UFTM

INTRODUÇÃO: A diarreia é um estado de desequilíbrio intestinal da qual culmina em desidratação, podendo levar ao óbito. O estado de diarreia está geralmente associado com infecções mediadas por contaminação fecal-oral ou ainda por desordens inflamatórias intestinais, das quais ocasionalmente se atrelam à fatores sazonais. As características ambientais do sudoeste goiano, assim como em várias regiões com clima tropical podem estar ligadas ao desenvolvimento de algumas desordens, incluindo a diarreia. OBJETIVO: Assim, o presente estudo objetivou avaliar a distribuição das ocorrências por diarreia em um município do sudoeste goiano. MÉTODOS: Estudo longitudinal e retrospectivo foi realizado no período de 2013 a 2019 no município de Mineiros, GO. Os dados do número de casos de diarreia foram reportados pela secretaria de saúde do município e avaliados quanto a correlação temporal e a influência dos meses na distribuição dos casos. RESULTADOS: Foram relatados 10.938 casos, dos quais apresentaram uma correlação negativa $(r=-0,96)$ e estatisticamente significativa $(p=0,002)$ quanto ao número de casos no período avaliado. Não houve diferenças nas distribuições por meses e nem entre os semestres anuais $(p>0,05)$. CONCLUSÃO: Juntos os dados permitem concluir que houve uma redução significativa dos casos de diarreia no período avaliado, entretanto a diarreia ainda é uma realidade do município, da qual não sobre influencia sazonal.

DESCRITORES: Diarreia; Sazonal; Sudoeste Goiano. 
ISSN 2447-9071

doi https://doi.org/10.36414/rbmc.v7i17.92

\section{Anais do XVII Congresso Brasileiro de Biomedicina e V Congresso Internacional de Biomedicina}

\section{Avaliação da toxicidade da formulação comercial do herbicida glifosato em sua forma original e encapsulada sobre a morfologia espermática, peso corpóreo e peso dos órgãos de camundongos}

Cíntia Gonçalves de Oliveira, Gabriel Adan Araujo Leite, Lucinéia dos Santos

Área: Toxicologia

Instituição de Origem: Faculdade de Ciências e Letras de Assis - UNESP, Universidade Federal de Santa Catarina - UFSC

INTRODUÇÃO: O glifosato tem sido apontado como potencial contaminante ambiental com riscos à saúde humana e animal. Assim, considerando o grande uso do Roundup na agricultura brasileira, justifica-se a execução de ensaios para determinar sua toxicidade e buscar novas tecnologias que possam reduzir seus riscos. OBJETIVO: Encapsular o herbicida Roundup por meio de duas diferentes técnicas e analisar in vivo os efeitos da formulação comercial em sua forma original e encapsulada em camundongos machos. MÉTODOS: $O$ encapsulamento do Roundup ${ }^{\oplus}$ foi realizado com quitosana ou com acetato de celulose extraída da fibra do sisal. Os camundongos ( $n=10 / g r u p o$ ) foram divididos em: controle (água mineral); glifosato ( $0,5 \mathrm{mg}$ de glifosato livre/L de água); acetato ou quitosana ( $0,5 \mathrm{mg}$ glifosato encapsulado em nanocápsulas/L de água). Tratados por 45 dias, foram eutanasiados no dia pós-natal 130 para obtenção do peso corpóreo, dos órgãos e espermatozoides para avaliação da morfologia espermática. RESULTADOS: O rendimento médio do processo de síntese de celulose foi de $44,1 \%$. A eficiência dos encapsulamentos foi de $16,86 \%$ para o acetato de celulose e $24,8 \%$ para quitosana. $O$ grupo tratado com o glifosato encapsulado com acetato de celulose apresentou redução no ganho de peso $(p<0,05)$. CONCLUSÃO: Nas condições testadas, o Roundup ${ }^{\circledast}$ não apresentou toxicidade, exceto no tratado com encapsulado com acetato, que promoveu alteração na evolução do peso, apresentando um possível efeito tóxico.

DESCRITORES: Nanocápsulas; Roundup ${ }^{\oplus}$; Quitosana; Acetato de celulose; Sisal. 
ISSN 2447-9071

doi https://doi.org/10.36414/rbmc.v7i17.92

\section{Anais do XVII Congresso Brasileiro de Biomedicina e V Congresso Internacional de Biomedicina}

\section{Avaliação de parâmetros inflamatórios em camundongos deficientes de interferon- $\gamma$ submetidos a infecção por trypanosoma cruzi}

Camila Botelho Miguel, Wellington Francisco Rodrigues, Melissa Carvalho Martins de Abreu, Javier Emilio Lazo Chica, Carlo José Freire Oliveira

Área: Outras da saúde

Instituição de Origem: Centro Universitário de Mineiros - UNIFIMES; Universidade Federal do Triângulo Mineiro - UFTM

INTRODUÇÃO: A resposta celular mediada por fagócitos e perfil T-helper $1 \mathrm{com}$ liberação de Interferon- $\gamma$ é um importante mecanismo imune que contribui na resposta contra a infecção pelo Trypanosoma cruzi (T. cruzi). Estudos indicam uma variação dessa resposta pode acontecer a depender da concentração do inoculo de T. cruzi no entanto a participação desta citocina nessa variação ainda não está claramente definida. OBJETIVO: Avaliar parâmetros inflamatórios e imune de camundongos deficientes da síntese de interferon- $\gamma$ infectados com diferentes inóculos de T. cruzi. MÉTODOS: Foram utilizados 18 camundongos C57BL/6 IFN-/-, conformando os grupos: Controle, Infectados com $3 \times 103$ e 3×104 formas tripomastigotas sanguíneas da cepa Y de T. cruzi, inoculados por via subcutânea. A quantificação de parasitos no sangue foi determinada diariamente. Foram coletados coração para quantificação do número de células e ninhos de T. cruzi por imunohistoquimica. RESULTADOS: A curva de parasitemia mostrou diferenças significativas entre os grupos analisados desde o $3^{\circ}$ ao $9^{\circ}$ dia após a infecção. Quanto à sobrevida, os animais do grupo 3×104 vieram a óbito após 12 dias de infecção, enquanto o grupo 3×103 após 13 dias. A contagem de células e ninhos de amastigotas mostrou diferenças significativas entre os grupos analisados, com aumento para o grupo $3 \times 104$. CONCLUSÃO: Assim, observa-se que quanto maior o inoculo, maiores são as alterações inflamatórias a nível sanguíneo e tecidual.

DESCRITORES: T. cruzi; Inoculos logarítmicos; Cepa Y; C57BL/6 IFN-/-. 
ISSN 2447-9071

doi https://doi.org/10.36414/rbmc.v7i17.92

\section{Anais do XVII Congresso Brasileiro de Biomedicina e V Congresso Internacional de Biomedicina}

\section{Avaliação dos casos de óbitos por hanseníase no Brasil}

Camila Botelho Miguel, Patrício Barbosa da Mota, Melissa Carvalho Martins de Abreu, Wellington Francisco Rodrigues

Área: Saúde Pública

Instituição de Origem: Centro Universitário de Mineiros - UNIFIMES; Universidade Federal do Triângulo Mineiro - UFTM

INTRODUÇÃO: A Hanseníase é uma patologia infecciosa provocada pelo bacilo Mycobacterium leprae. A doença é disseminada por todas as regiões do país e apesar dos esforços de combate e intensificação à prevenção, a Hanseníase ainda é considerada um problema de saúde pública. OBJETIVO: Avaliar os casos de óbitos por Hanseníase nas macrorregiões brasileiras. MÉTODOS: Foi realizada uma busca de dados relacionados às ocorrências de óbitos por causas relacionadas à Hanseníase nas diferentes Unidades Federativas do Brasil no período de 2008 a 2018 através da base de dados do Ministério da Saúde (DATASUS). Posteriormente, estes dados foram normalizados por 100 mil habitantes com base na densidade populacional obtida através do site IBGE. RESULTADOS: Observouse que há diferenças significativas entre as várias Unidades Federativas do Brasil em relação ao número de óbitos por Hanseníase. Entre todos os estados brasileiros, a análise desses parâmetros evidenciou dois Estados com correlações significativas, Mato Grosso e Tocantins. Além disso, houve índices importantes e significativos, em relação à presença de incapacidade física nos casos de Hanseníase no período analisado, das regiões Nordeste e Centro-Oeste em relação as demais. CONCLUSÃO: Portanto, a doença ainda é uma realidade no país e apresenta prevalência elevada em algumas macrorregiões. Medidas intensivas são necessárias para os próximos anos para que seja alcançada a diminuição de casos da doença.

DESCRITORES: Hanseníase; Epidemiologia; Brasil. 


\section{Anais do XVII Congresso Brasileiro de Biomedicina e V Congresso Internacional de Biomedicina}

\section{Perfil clínico e epidemiológico de pacientes atendidos em uma unidade laboratorial de Maceió/AL para sorologia de Covid-19}

Hiago Santos Amorim, Lucas dos Santos Ferreira, Mayara Acioli Cedrim, Thaís Raiol Figueredo, Fabíola de Almeida Brito, Marcia Raquel Cedrim Vieira

Área: Análises Clínicas

Instituição de Origem: Centro Universitário CESMAC; Universidade Maurício de Nassau; Faculdade Estácio.

INTRODUÇÃO: Em dezembro de 2019, em Wuhan, na China, foram relatados casos de uma pneumonia de causa desconhecida com frequência mais alta que o normal. Os laboratórios locais descobriram que se tratava de uma infecção causada por uma nova cepa de vírus, da família Coronaviridae, mais conhecido como coronavírus, recebendo o nome de Síndrome Respiratória Aguda Grave do Coronavírus 2 (SARS-COV-2). Em 11 de março do ano de 2020, o surto foi considerado pandemia pela OMS. Atualmente o Brasil apresenta mais de 5.000 .000 de casos, e aproximadamente 150.000 óbitos segundo dados do Datasus. Comorbidades e faixa etária elevada sinalizam como características de maior propensão ao aparecimento de complicações secundárias ao contato com o vírus. OBJETIVO: Descrever o perfil clínico e epidemiológico de pacientes que apresentaram sorologia positiva de COVID-19 atendidos em uma unidade laboratorial de Maceió/AL e avaliar os dados obtidos com a literatura para auxiliar no conhecimento e combate à doença, observando variáveis como faixa etária, sexo, comorbidade pré-existentes e sintomas apresentados. MÉTODOS: Os dados foram obtidos por consultas nos registros pertencentes ao arquivo eletrônico da unidade laboratorial do município de Maceió-AL, no período compreendido entre abril de 2020 a agosto de 2020. RESULTADOS: Durante o período analisado 260 pacientes com idade prevalente entre 31 a 50 anos realizaram exames laboratoriais específicos para detecção do SARS-COV-2. Dos pacientes que realizaram sorologia para COVID-19 no período avaliado, $41,9 \%$ da faixa etária de 31-50 anos, foram do sexo masculino e 22,1\% foram do sexo feminino da mesma faixa etária, sendo a maior prevalência o sexo masculino. Dentre as comorbidades, as de maior prevalência foram Diabetes e Hipertensão. CONCLUSÃO: Com a análise detalhada dos dados foi possível verificar uma relação entre a idade e a prevalência da infecção viral nessa mesma faixa etária, e concluiu-se que estão diretamente proporcionais à idade e possíveis comorbidades pré-existentes.

DESCRITORES: COVID-19; Epidemiologia; Sorologia. 
ISSN 2447-9071

doi https://doi.org/10.36414/rbmc.v7i17.92

\section{Anais do XVII Congresso Brasileiro de Biomedicina e V Congresso Internacional de Biomedicina}

\section{Determinação do teor de compostos fenólicos em extrato de morango in natura}

Rhaysa Akemi Takeda Santos, Talita Raissa Scherer, Angélica dos Santos Marchi de Lima, Paula Maria Carneiro Rocha, Lorena Calina Silveira, Kimiyo Shimomura Haida

Área: Análise Bromatológica

Instituição de Origem: Universidade Paranaense

INTRODUÇÃO: O morango é um dos frutos de maior consumo no Brasil, com alto valor nutricional e flavonoides. Compostos fenólicos são responsáveis pela ação antioxidante contra radicais livres. OBJETIVO: Determinar o teor de compostos fenólicos em extrato aquoso e cetônico de morangos in natura. MÉTODOS: Os morangos in natura foram obtidos no comércio de Cascavel-PR, higienizados, triturados e homogeneizados. Pesou-se $30 \mathrm{~g}$ para o preparo dos extratos. Para o extrato aquoso usou-se $40 \mathrm{~mL}$ de água destilada agitando por $50 \mathrm{~min}$. foi coado e levado à centrífuga a $1.500 \mathrm{rpm}$ por $15 \mathrm{~min}$. Somou-se $40 \mathrm{~mL}$ de água destilada aos resíduos, agitados e centrifugados. Acresceu-se água destilada ao extrato para atingir o volume final de $100 \mathrm{~mL}$. Usou-se o mesmo processo para o extrato cetônico, com acetona 70\%. O teor de composto fenólico foi determinado pelo método de Folin-Ciocalteau. Misturou-se $500 \mu \mathrm{l}$ de extrato e $2 \mathrm{~mL}$ de solução de Folin-Ciocalteau, deixado em repouso por $15 \mathrm{~min}$ no escuro. Foi somado $2 \mathrm{~mL}$ de $\mathrm{CaCO} 37,5 \%$ e posto em repouso por $1 \mathrm{~h}$ no escuro. Leitura por espectrofotômetro a $700 \mathrm{~nm}$. amostras em triplicata e quantificadas por uma curva padrão de ácido gálico. RESULTADOS: Com a curva padrão de ácido gálico foi encontrado $R 2=0,9503$ e a equação de: $C=0,089+0,07$. Os

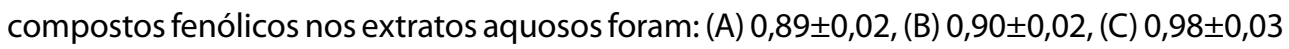
E nos extratos cetônicos: (A)1,00 $\pm 0,03,(B) 1,13 \pm 0,04,(C) 1,20 \pm 0,05 \mathrm{mg}$. CONCLUSÃO: 0 extrato cetônico de morangos in natura apresentou maior teor de compostos fenólicos que em extrato aquoso.

DESCRITORES: Composto fenólico; Morango. 
ISSN 2447-9071

doi https://doi.org/10.36414/rbmc.v7i17.92

\section{Anais do XVII Congresso Brasileiro de Biomedicina e V Congresso Internacional de Biomedicina}

\section{Efeitos da dieta de baixo teor de carboidratos e alto teor de gordura associada ou não ao treinamento resistido sobre a hipertrofia e fibrose do ventrículo cardíaco esquerdo de ratos}

Bianca Caruso Moreira, Uliana Sbeguen Stotzer, Heloisa Sobreiro Selistre de Araujo

Área: Biologia Molecular e genética

Instituição de Origem: Universidade Federal de São Carlos - UFSCar

INTRODUÇÃO: A obesidade é um fator de risco para o desenvolvimento de doenças cardiovasculares. Para combater a obesidade e promover a saúde cardiovascular, a utilização da dieta Low carb/High fat (LCHF) e treinamento resistido (TR) podem ser importantes estratégias. Contudo, pouco se sabe sobre a segurança da dieta LCHF associado ao TR na saúde cardiovascular em longo prazo. OBJETIVO: Verificar a segurança em longo prazo que a dieta LCHF associada ao TR na fibrose e hipertrofia do ventrículo esquerdo. MÉTODOS: Trinta e oito ratos Sprague Dawley foram aleatorizados nos grupos: i) dieta controle/sedentário (DC-S n=9); ii) dieta controle/treinado (DC-T $n=9$ ); iii) dieta LCHF/ sedentário (LCHF-S $n=9$ ) e; iv) dieta LCHF/treinado (LCHF-T $n=11$ ). Os animais passaram pelo período experimental de 10 semanas. Analisamos o conteúdo de fibras colágenas por picrosirius e hipertrofia dos cardiomiócitos por HE. RESULTADOS: Encontramos valores similares no conteúdo de fibras colágenas entre grupos (DC-S: 19,36\%; DC-T: 16,68\%; LCHF-S: 17,23\%; e LCHF-T: 17,24\%) (P > 0,05). Com relação a hipertrofia, não houve diferença no

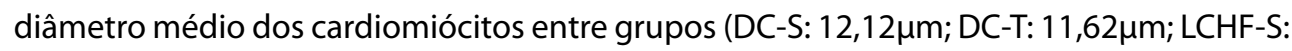

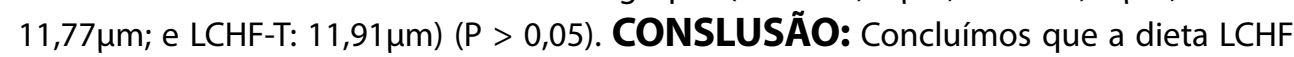
associada ou não ao TR não provoca hipertrofia nem fibrose do VE pelo período de tempo analisado, sugerindo ausência de efeitos maléficos sobre o coração.

DESCRITORES: Coração; Fibrose; Treinamento Resistido; Dieta. 


\section{Anais do XVII Congresso Brasileiro de Biomedicina e V Congresso Internacional de Biomedicina}

\section{Estudo in sílico para análise molecular da esclerose múltipla}

Ubiratan Mendes Rodrigues, Nazanda Santos Nassif, Marcus Vinicius Cardoso Matos Silva

Área: Genética, Bioinformática

Instituição de Origem: Universidade Salvador - UNIFACS

INTRODUÇÃO: O uso das tecnologias in sílico permite validar processos que antecedem a Reação em Cadeia da Polimerase (PCR), técnica que possibilita o monitoramento de doenças genéticas. Os oligonucleotídeos (primers) são usados na PCR delimitando a região de amplificação. Existem parâmetros essenciais para o desenho de primers - funcionalidade e especificidade. A esclerose múltipla (EM) é uma doença crônica e autoimune desmielinizante desencadeada por células T autorreativas. O gene HIES -STAT3 (transdutor de sinal e ativador de transcrição 3) codifica proteínas para respostas imunes e diferenciação. Foi observado a presença do STAT3 células T circulantes de pacientes com EM. OBJETIVO: Construção e validação in sílico de um par de primers para análise molecular da EM a partir do gene HIES. MÉTODOS: Utilizou-se o GenBank do NCBI para obter o sequenciamento do gene HIES. No Primer 3 Plus, obteve os pares de primers (forward e reverse) que atendessem aos valores do tamanho $(22 \mathrm{pb})$ temperatura de melting $\left(50-70^{\circ} \mathrm{C}\right)$ - a temperatura necessária para dissociação das fitas sintetizada - e percentual de citosina e guanina (40-60\%). No Oligo Analyzer verificou-se a possibilidade de formação de estruturas indesejáveis, como o hairpin (auto anelamento), formação de ligações entre primers da mesma classe ou diferentes (self-dimer e hetero-dimer). RESULTADOS: O gene HIES apresentou cinco possibilidades de pares de primers. O primeiro par, o primer Forward obteve chances de formação das alças do tipo Hairpin, pela proximidade das temperaturas de Melting $\left(54.5^{\circ} \mathrm{C}\right)$ e do Hairpin $\left(33.4^{\circ} \mathrm{C}\right)$. Para garantir segurança deve-se ter, uma diferença de no mínimo $20^{\circ} \mathrm{C}$. O segundo par, o primer Reverse, também apresentou diferença não recomendada, sendo $53.4^{\circ} \mathrm{C}$ para dissociação e $42.7^{\circ} \mathrm{C}$ para Hairpin. O mesmo acontece no terceiro par. As ligações Self-dimer e hetero-dimer não podem ultrapassar valores excedente a $20 \%$ do tamanho do primer, por isso o quarto par é eliminado por apresentar $8 \mathrm{pb}$ submetidas as ligações do tipo self- dimer. O quinto par candidato, Forward (5'GGAGGGTAAATCTGGCTTTTCT 3') e Reverse (5' GTCAACTCCATGTCAAAGGTGA 3') foram validados por respeitarem os parâmetros de qualidade. Apresentaram, 22pb, garantindo uma adesão específica; respeitou a proporção de Citosina e Guanina, que garante mais estabilidade a fita, com $45.5 \%$; o primer Forward e Reverse obtiveram a temperatura de Melting e a formação das alças de Hairpin com mais de $20^{\circ} \mathrm{C}$ de diferença; as estruturas secundárias adversas, o Self-dimer e o Hetero-dimer não apresentaram chances altas de acometimento, garantindo a eficiência da amplificação. CONCLUSÃO: É possível destacar que, para o estudo que associa o gene HIES e esclerose múltipla, o quinto par de primer é validado in sílico, como já demonstrado em pesquisas, por dispor dos parâmetros corretos de uso.

DESCRITORES: Esclerose Múltipla; Gene HIES; STAT3; Primers. 


\section{Anais do XVII Congresso Brasileiro de Biomedicina e V Congresso Internacional de Biomedicina}

\section{Frequência Polimorfismo CYP2C19*2 em Pacientes com dislipidemia e aterosclerose}

Oximano da Silva Dias Neto, Andreia Marcelino Barbosa, lasmim Ribeiro da Costa, Isabela Barros Lima, Ulisses dos Santos Vilarinho, Thais Regina dos Santos, Kátia Karina Verolli de Oliveira Moura

Área: Genética

Instituição de Origem: Pontifícia Universidade Católica de Goiás; Universidade Federal de Goiás; Universidade de São Paulo

INTRODUÇÃO: A aterosclerose uma doença inflamatória sistêmica progressiva, associada à deposição de lipídeos e fibroses em placas na parede arterial. O gene CYPC19 é codificado no locus 10q24.1-10q24.3 do cromossomo 10, composto por nove éxons e oito íntrons. Sendo descritas cerca de 448 variantes alélicas, variando de atividade enzimática nula a aumentada, sendo que 50 variantes genômicas do CYP2C19 foram identificadas. OBJETIVO: Analisar o polimorfismo do gene CYP2C19*2 em pacientes ateroscleróticos em uso de estatinas, analisando um grupo experimental com stent e um grupo controle sem stent para realizar uma comparação da terapêutica das estatinas. MÉTODOS: Foram coletadas 80 amostras de sangue periférico de pacientes com aterosclerose e dislipidemia diagnosticado através de exames clínicos e imagem e foram classificados pela presença do stent. As análises foram realizadas a partir de extração de DNA das amostras, submetidas a PCR. RESULTADOS: Ao se analisar a relação do stent com o polimorfismo foi identificado que no grupo com stent $28,6 \%$ apresentaram CYP2C19*2 ${ }^{*} 1 /{ }^{*} 1$ (10/35), 31,4\% CYP2C19*2*1/*2 (11/35), 40\% CYP2C19*2*2/*2 (14/35), já no grupo sem stent foi evidenciado $28,9 \%$ CYP2C19*2* $1 *{ }^{*} 1(13 / 45), 33,3 \%$ CYP2C19*2* $1 /{ }^{*} 2(15 / 45)$ e $37,8 \%$ CYP2C19*2*2/*2 (17/45). Não foi encontrada nenhuma diferença estatisticamente significante $(p=0.9764)$. CONCLUSÃO: A partir dos resultados desse trabalho foi encontrado uma prevalência de indivíduos homozigotos para o alelo *2 polimórfico, e segundo a literatura portadores homozigóticos do alelo *2 apresentam perda de função da enzima e confere um metabolismo pobre.

DESCRITORES: Aterosclerose; CYP2C19*2; Polimorfismo; Stent; Estatinas. 
ISSN 2447-9071

doi https://doi.org/10.36414/rbmc.v7i17.92

\section{Anais do XVII Congresso Brasileiro de Biomedicina e V Congresso Internacional de Biomedicina}

\section{Hemoglobina glicada (HbA1c) para a avaliação do controle glicêmico e para o diagnóstico dos diabetes}

Ester Nunes Gontijo, Marcus Alisson Araújo da Cunha

Área: Análises Clínicas

Instituição de Origem: Faculdade Anhanguera de Brasília

INTRODUÇÃO: O diabetes mellitus (DM) são um grupo de doenças causadas por irregularidades no metabolismo dos carboidratos, lipídeos e aminoácidos, entretanto os carboidratos aparecem com maior prevalência nos diagnósticos. A HbA1c é uma hemoglobina que se liga a glicose, essa ligação é chamada de glicosilação. Para a avaliação do controle glicêmico, utiliza-se o exame de hemoglobina glicada. A HbA1c torna indubitável o controle médio nos últimos três meses. Quanto maior estiverem os níveis de glicose, aumenta a glicosilação, estimulando a produção acentuada de hemoglobina glicada. OBJETIVO: Avaliar o controle glicêmico e diagnosticar os diabetes mellitus, através da hemoglobina glicada. MÉTODOS: Trata-se de um estudo descritivo de teses e observações de diversos autores e também publicações de organizações mundiais sobre o diabetes. RESULTADOS: De acordo com a federação mundial de diabetes (International Diabetes Federation, IDF), em 2019, pessoas com idades entre 20- 70 anos, cerca de 463 milhões de adultos, viviam com diabetes e acredita-se que no ano de 2045 o número de diabetes aumentará para 700 milhões. A IDF constatou que os diabetes é responsável por provocar 4,2 milhões de mortes. CONCLUSÃO: Conclui-se que o diabetes mellitus tem tido acréscimos no decorrer dos anos, essa doença pode trazer várias complicações. $A$ hemoglobina glicada é um exame essencial para avaliar o controle glicêmico e diabetes, sendo indicada para todos os diabetes.

DESCRITORES: Controle Glicêmico; Diabetes; Diagnóstico; Hemoglobina Glicada. 
ISSN 2447-9071

doi https://doi.org/10.36414/rbmc.v7i17.92

\section{Anais do XVII Congresso Brasileiro de Biomedicina e V Congresso Internacional de Biomedicina}

\section{Investigação de variantes nas regiões não codificantes dos genes BRCA1 e BRCA2: Importância e atribuição ao diagnóstico da Síndrome do Câncer de Mama e Ovário Hereditários (HBOC)}

Kayana Isabel Weber de Souza, Tiago Finger Andreis, Patricia Ashton-Prolla, Clévia Rosset

Área: Biologia Molecular e Genética

Instituição de Origem: Hospital de Clínicas de Porto Alegre

INTRODUÇÃO: Uma parcela significativa dos pacientes com fenótipo clínico da Síndrome do Câncer de Mama e Ovário Hereditários (HBOC) não apresenta variantes patogênicas nas regiões codificantes dos principais genes associados, $B R C A 1$ e $B R C A 2$, nem em outros genes associados à síndrome. As regiões não codificantes não são incluídas nos testes genéticos comercialmente disponíveis e poderiam apresentar variantes patogênicas nesses casos. OBJETIVO: Verificar a frequência de variantes descritas nas regiões não codificantes de $B R C A 1 / 2$ no Brasil e em outros países revisar a literatura sobre os aspectos funcionais das mesmas. MÉTODOS: Busca por variantes germinativas nas regiões de interesse no banco de dados brasileiro $\mathrm{ABRaOM}$, e comparação com bancos internacionais ClinVar, HGMD e LOVD ${ }^{3}$. Com o uso de palavras-chaves no Pubmed, foram selecionados artigos científicos que abordaram aspectos funcionais de variantes nestas regiões. RESULTADOS: Foram avaliadas 129 variantes para BRCA1 e 138 para BRCA2, das quais apenas uma foi classificada como patogênica. Em comparação a outros países, houve menor número de variantes reportadas no Brasil. Os estudos funcionais ainda não são suficientes para classificar variantes na região não codificante de BRCA1/2. CONCLUSÃO: O baixo número de variantes reportadas e estudos envolvendo essas regiões indicam um potencial para investigações adicionais, especialmente no Brasil, podendo representar uma mudança de paradigma no manejo destes indivíduos.

DESCRITORES: Síndrome de Câncer de Mama e Ovários Hereditários; Região Não Codificante; Variantes Genéticas; Bancos de Dados. 
ISSN 2447-9071

doi https://doi.org/10.36414/rbmc.v7i17.92

\section{Anais do XVII Congresso Brasileiro de Biomedicina e V Congresso Internacional de Biomedicina}

\section{Investigação in silico CYP1A1 - catenina no glaucoma e a determinação de métodos terapêuticos}

Isabela Barros Lima, Ulisses dos Santos Vilarinho, Andreia Marcelino Barbosa, Kátia Karina Verolli de Oliveira Moura, Kleber Santiago Freitas e Silva.

Área: Informática de Saúde

Instituição de Origem: Pontifícia Universidade Católica de Goiás

INTRODUÇÃO: O glaucoma é uma neuropatia óptica que pode levar à cegueira irreversível. O gene do citocromo P450 (CYP) é responsável pela defesa contra xenobióticos, metabolizar vitaminas lipossolúveis, ácidos graxos e esteróides. A catenina está envolvida no metabolismo de drogas e xenobióticos A bioinformática pode ser usada para desenvolver novos métodos de diagnóstico e terapia. OBJETIVO: Analisar a interação in silico entre duas proteínas relacionadas com o glaucoma e planejar um peptídeo modulador a ser testado in vivo e in vitro como terapia para o glaucoma. MÉTODOS: Foi utilizado o servidor I-TASSER para modelar a proteína CYP1A1. A estrutura da catenina está disponível no PDB. A área de interação foi definida pelo servidor ClusPro e todas as estruturas 3-D foram visualizadas e analisadas pelo PyMol. Os hotspots foram analisadas através do KFC2. Os resíduos polimórficos foram identificados através do dbSNP. RESULTADOS: A sequência de aminoácidos do CYP1A1 e da catenina foram recuperadas do Centro Nacional de Informações Biotecnológicas (NCBI). Observaram-se doze hotspots: oito estão no CYP1A1 e quatro na catenina. Os peptídeos produzidos apresentaram as respectivas sequências:TEFLLASVIF, GPWGWPLIGH e ENIQRVAAGV.CONCLUSÃO: A bioinformática e a abordagem in silico são maneiras de desenvolver peptídeos que podem ser usados como opções de tratamento. Porém, o alto custo das abordagens experimentais e a demora dos procedimentos são fatores limitantes.

DESCRITORES: Glaucoma; Polimorfismo; Bioinformática; Genética; In silico. 
ISSN 2447-9071

doi https://doi.org/10.36414/rbmc.v7i17.92

\section{Anais do XVII Congresso Brasileiro de Biomedicina e V Congresso Internacional de Biomedicina}

\section{O conhecimento sobre HIV/AIDS entre estudantes de medicina e de outros cursos de ensino superior no Rio de Janeiro, Brasil}

Caroline Graça Mota Damasceno, Fernanda Bonorino Carvalho de Mello, Patrícia de Oliveira Camera, Jéssica Leite da Silva, Ivi Cristina Menezes de Oliveira

Área: Educação em Saúde

Instituição de Origem: Fundação Técnico-Educacional Souza Marques - FTESM

INTRODUÇÃO: Após quase quarenta anos da descoberta do HIV, a falta de informação sobre a doença ainda é uma barreira a ser enfrentada. Atualmente, o acesso à informação aumentou, porém, não significou a quebra de estigmas, principalmente sobre transmissão e tratamento. OBJETIVO: Avaliar o conhecimento sobre HIV/AIDS dos estudantes de medicina e outras áreas de ensino superior do Rio de Janeiro, Brasil. MÉTODOS: Utilização de questionário online com 14 perguntas de múltipla escolha sobre perfil social e conhecimentos gerais de transmissão e profilaxia de HIV/AIDS, sendo criado pelo GoogleDocs aplicado em 154 pessoas, sendo 95 alunos do curso de medicina e 59 alunos de outros cursos. RESULTADOS: Na comparação das respostas sobre conhecimentos gerais, todos conheciam algum tipo de prevenção contra Infecções Sexualmente Transmissíveis. Dessas, a Profilaxia Pós-Exposição é mais conhecida do que Profilaxia Pré-Exposição. Com relação às questões acerca de transmissão da doença, os estudantes de medicina tiveram um melhor conhecimento. CONCLUSÃO: Ambos os grupos obtiveram um bom rendimento geral acerca dos conhecimentos testados, somente na parte de transmissão, o conhecimento do grupo de outras áreas foi menor. Os achados são semelhantes a outros estudos e mostram a necessidade de maior divulgação de conteúdos sobre o HIV, uma vez que quanto maior o conhecimento sobre o vírus, maior a sua capacidade de prevenção e menor o estigma social para com seus portadores.

DESCRITORES: HIV; Epidemiologia; Tratamento; PEP; PrEP; transmissão. 
ISSN 2447-9071

doi https://doi.org/10.36414/rbmc.v7i17.92

\section{Anais do XVII Congresso Brasileiro de Biomedicina e V Congresso Internacional de Biomedicina}

\section{O HPV e o câncer do colo de útero: o conhecimento sobre o agente etiológico e a doença entre médicos, estudantes de medicina e a população geral no Rio de Janeiro, Brasil}

Elisa Yuki Kurosawa Ueda, Joanna de Araujo Frisso, Patricia de Oliveira Camera, Jéssica LeiteSilva, Ivi Cristina Menezes de Oliveira

Área: Educação em Saúde

Instituição de Origem: Fundação Técnico-Educacional Souza Marques - FTESM

INTRODUÇÃO: Mulheres em todo o mundo são acometidas pelo câncer de colo de útero, sendo mais de $80 \%$ dos casos em países em desenvolvimento. Dentre as causas, a infecção por Papilomavírus Humano (HPV) é a principal. OBJETIVO: Avaliar o conhecimento de médicos e estudantes de Faculdades de Medicina no Estado do Rio de Janeiro e o conhecimento da população fluminense sobre a infecção pelo HPV. MÉTODOS: Utilização de questionário online com 15 perguntas de múltipla escolha sobre perfil social e conhecimentos gerais sobre a doença, criado e aplicado via GoogleDocs para 200 pessoas, sendo 100 graduandos de medicina e médicos, e 100 pessoas que compõem a população geral. RESULTADOS: Na comparação das respostas sobre conhecimento da doença, nota-se conhecimento satisfatório sobre transmissão e a relação entre HPV e o câncer de colo uterino em ambas populações, porém, observou-se baixa taxa de acerto sobre sorotipos de baixo risco oncogênico. Em relação à prevenção, nota-se percentagem de acertos equivalentes entre as populações médica e geral. CONCLUSÃO: As respostas foram, na sua maioria, esperadas para cada população. A maioria dos erros foi relacionada a tipos virais e público alvo da vacinação. Espera-se que aumentando o conhecimento da população geral e médica, haja um aumento da profilaxia e maior cuidado na relação sexual, uma vez que se diminuem as chances de infecção por HPV e, consequentemente, diminui-se a incidência de câncer de colo de útero.

DESCRITORES: HPV; Câncer do Colo de Útero; Tratamento; Profilaxia. 
ISSN 2447-9071

doi https://doi.org/10.36414/rbmc.v7i17.92

\section{Anais do XVII Congresso Brasileiro de Biomedicina e V Congresso Internacional de Biomedicina}

\section{O uso da procalcitonina como biomarcador para sepse em um hospital privado na cidade de Macapá-AP}

Vinicius Yuri Borges dos Santos, Gleicyanne Furtado Frazão, Lyvia de Oliveira Matias Fonseca, Mailson de Paula Freitas Rodrigues

Área: Análises Clínicas

Instituição de Origem: MR Sciencelab

INTRODUÇÃO: A sepse é uma manifestação desregulada do organismo durante a tentativa de conter uma proliferação de um agente patogênico, e vem se tornando cada vez mais frequente na rotina hospitalar. OBJETIVO: Avaliar a eficácia da procalcitonina como biomarcador no prognóstico de sepse. MÉTODOS: Após aprovação do Comitê de Ética em Pesquisa foram realizadas dosagens do nível de procalcitonina em pacientes com quadro sintomático de sepse, e que aceitaram participar da pesquisa e registraram em Termo de Consentimento Livre e Esclarecido - TCLE. RESULTADOS: Durante o período de coleta deste estudo foram atendidos 6 pacientes, onde dois casos foram confirmados para Sepse. Como esperado, estes pacientes confirmados demonstraram elevação nos níveis de procalcitonina nas horas iniciais de hospitalização e significativa redução após o período de 24 horas. Os demais pacientes não obtiveram níveis positivos de procalcitonina na dosagem inicial e nem após 24 horas e, posteriormente, foram confirmados não se tratar sepse através de hemocultura, ficando o protocolo aberto como diagnóstico diferencial. CONCLUSÃO: Neste estudo a dosagem da procalcitonina se mostrou eficaz no prognostico de sepse, e por ser um teste rápido e de baixo custo demonstrou potencial, porém necessita de pesquisas mais amplas.

DESCRITORES: Procalcitonina; Sepse; IRAS; Prognóstico. 
ISSN 2447-9071

doi https://doi.org/10.36414/rbmc.v7i17.92

\section{Anais do XVII Congresso Brasileiro de Biomedicina e V Congresso Internacional de Biomedicina}

\section{Panorama de casos das meningites no período de 2007 a 2019 na Bahia, Brasil}

Fernanda Lopes Habib, Gabriela Cruz Lima, Thayná Torres Gonzalez, Victória Cruz Paraná, Artur Gomes Dias Lima, Viviane de Matos Ferreira, Suzana Ramos Ferrer

Área: Saúde Pública

Instituição de Origem: Escola Bahiana de Medicina e Saúde Pública

INTRODUÇÃO: As meningites são consideradas um grande problema de saúde pública, sendo a Bahia um dos estados com maior incidência de casos anuais no Brasil. OBJETIVO: Analisar a distribuição dos casos e letalidades por meningites na Bahia, entre os anos de 2007 a 2019. MÉTODOS: Trata-se de um estudo ecológico descritivo, com informações do Sistema Nacional de Agravos e Notificações (SINAN). Foram levantados e analisados os casos de meningites, por etiologia, disponíveis na base de dados do SINAN. RESULTADOS: A Meningite viral (MV) apresentou a maior número de casos confirmados, com uma média de 541 notificações, seguido por Meningite não especificada (MNE) e Meningite bacteriana (MB), com uma média de 168,6 e 167,8 casos anuais, respectivamente. Porém, a partir do ano de 2012, os casos de MV diminuíram, enquanto a MNE e MB se mantiveram constantes. Apesar da MV ter apresentado maior número de casos, o número de óbitos não esteve entre os mais altos, comparado às demais etiologias. A MB demonstrou um pico de óbitos em 2009 (45/248; 18,1\%), e, nos anos seguintes, apresentou declínio. A MNE exibiu um dos valores mais altos e se manteve constante durante os anos, com uma média de 24 óbitos. CONCLUSÃO: É necessário se investir no reconhecimento da MNE para melhor diagnóstico e tratamento. Além disso, se faz necessária a atenção permanente da vigilância epidemiológica e da cobertura vacinal das demais etiologias, para controle de possíveis novos surtos.

DESCRITORES: Meningites; Bahia; Casos; Óbitos; Cobertura Vacinal. 
ISSN 2447-9071

doi https://doi.org/10.36414/rbmc.v7i17.92

\section{Anais do XVII Congresso Brasileiro de Biomedicina e V Congresso Internacional de Biomedicina}

\section{Perfil de resistência aos antimicrobianos em infecções do trato urinário causadas por Escherichia coli}

Camila Lima Guimarães, Carolina Braga Borges, Maria Clara Ribeiro Figueiredo, Matheus Medeiros Aguiar, Elisa Lima Vieira, Melissa Carvalho Martins de Abreu, Marcelo Costa Araújo, Wellington Francisco Rodrigues, Camila Botelho Miguel

Área: Análises Clínicas

Instituição de Origem: Centro Universitário de Mineiros - UNIFIMES, Universidade Federal do Triângulo Mineiro - UFTM

INTRODUÇÃO: As Infecções do Trato Urinário (ITU) e suas complicações são uma das principais causas de morbimortalidade no mundo. A Escherichia coli (E. coli) é responsável por cerca de $80 \%$ das infecções urinarias em pacientes ambulatoriais e geralmente é tratada empiricamente. OBJETIVO: Avaliar o perfil de resistência antimicrobiana para E. coli em uroculturas de indivíduos atendidos por um Programa de Atenção Domiciliar no município de Mineiros/GO. MÉTODOS: Foram avaliadas uroculturas com antibiograma de indivíduos atendidos por programa de atenção domiciliar no município de Mineiros/GO no período de janeiro/2018 a março/2020. Dos resultados encontrados, foram computados aqueles positivos para E. coli e avaliado o perfil de resistência antimicrobiana. RESULTADOS: Foram analisados 112 exames, sendo 51 negativos, 61 positivos para algum micro-organismo e destes, 17 para E. coli. Quanto ao perfil do antibiograma, foram observados $100 \%$ de resistência para Ampicilina, 82,4\% para Ciprofloxacina e Norfloxacina, 64,7\% para Amoxicilina + Ácido Clavulânico, 62,5\% para Cefotaxima, 52,9\% para Sulfa-Trimetropim, 41,2\% para Ceftriaxona, 33,3\% para Cefaclor e Cefazolina e 30,8\% para Cefalexina. Já para Amicacina, Cefoxitina, Fosfomicina e Nitrofurantoína apresentaram $100 \%$ de sensibilidade para as amostras avaliadas. CONCLUSÃO: Assim, pode-se observar um aumento no perfil de resistência antimicrobiana nesta população, dificultando a escolha de um tratamento eficaz.

DESCRITORES: Urocultura; E. coli; Atenção Domiciliar. 
ISSN 2447-9071

doi https://doi.org/10.36414/rbmc.v7i17.92

\section{Anais do XVII Congresso Brasileiro de Biomedicina e V Congresso Internacional de Biomedicina}

\section{Perfil epidemiológico de mortalidade por febre amarela no Brasil entre 2011 a 2018}

Luma Gabriella Santos Toledo, Késsia Gomes Pinto, Pollyana Silva Nonato Pereira, Ricardo Cambraia Parreira, Melissa Carvalho Martins de Abreu, Wellington Francisco Rodrigues, Camila Botelho Miguel

Área: Saúde Pública

Instituição de Origem: Centro Universitário de Mineiros - UNIFIMES; Universidade Federal do Triângulo Mineiro - UFTM

INTRODUÇÃO: A Febre Amarela é uma doença viral, infecciosa, aguda caracterizada por dois ciclos de transmissão epidemiológica: silvestre e urbano. $O$ vírus da Febre Amarela ressurgiu em dezembro de 2016 na região Sudeste do Brasil, causando um surto no Brasil. OBJETIVO: Avaliar os casos de óbitos por Febre Amarela no Brasil entre 2011 a 2018. MÉTODOS: Foi realizada uma busca de dados relacionados às ocorrências de óbitos por Febre Amarela no Brasil. Em seguida, verificou-se os índices na região Sudeste e nos estados que fazem parte desta macrorregião no período de 2011 a 2018 através da base de dados do Ministério da Saúde (DATASUS). Posteriormente, estes dados foram normalizados por 100 mil habitantes com base na densidade populacional obtida na mesma plataforma. RESULTADOS: Observou-se um aumento dos índices de óbitos por Febre Amarela no Brasil entre os anos de 2017 a 2018. Ao avaliar os casos por região, observou-se que a região Sudeste obteve maiores números. Em seguida realizou-se uma correlação entre os estados da região Sudeste nos anos de 2011 a 2018, destacando assim o estado de Minas Gerais, uma correlação positiva e significativa. CONCLUSÃO: Desta forma, podemos concluir que a Febre Amarela ainda é uma realidade no Brasil. Assim, políticas públicas devem ser intensificadas afim de controlar os novos casos no Brasil.

DESCRITORES: Febre Amarela; Epidemiologia; Brasil. 
ISSN 2447-9071

doi https://doi.org/10.36414/rbmc.v7i17.92

\section{Anais do XVII Congresso Brasileiro de Biomedicina e V Congresso Internacional de Biomedicina}

\section{Prevalência da variante p.Trp323Ter no gene CBS em pacientes brasileiros com Homocistinúria Clássica e associação fenotípica}

Gabriela Garcia Silvano, Soraia Poloni, Emilia Katiane Embiruçu, Giovana Weber-Hoss, Gustavo Mottin Rizowy, Karina Colonetti, Patrícia Pontes Cruz, Taciane Borsatto, Ida Vanessa Doederlein Schwartz

Área: Biologia molecular e genética

Instituição de Origem: Hospital de Clínicas de Porto Alegre

INTRODUÇÃO: A Homocistinúria Clássica (HCU) é um erro inato do metabolismo causado pela deficiência da enzima cistationina-beta-sintase. Em estudo prévio, a variante Saudita rara p.Trp323Ter (c.969G >A) foi identificada com prevalência de 11,3\% em pacientes brasileiros. OBJETIVO: Descrever o perfil clínico e bioquímico dos pacientes brasileiros com HCU portadores da variante p.Trp323Ter. MÉTODOS: Estudo transversal, na qual a identificação da variante p.Trp323Ter em pacientes com HCU foi realizada através da reação de PCR convencional, purificado e sequenciado por Sanger. A análise de dados de exames laboratoriais e manifestações clínicas foi através de consulta aos prontuários médicos. RESULTADOS: Dentre os pacientes brasileiros analisados ( $n=76)$, foram encontrados dez (sexo masculino $n=6$, mediana de idade $=15$ anos) que apresentaram a variante p.Trp323Ter, todos oriundos da Bahia e não responsivos à piridoxina. A média dos níveis de Hcy total foi de 191,8 \pm 103,6 $\mu \mathrm{mol} / \mathrm{L}$ (VR 5-15) e de Met $330 \pm 397,6 \mu \mathrm{mol} / \mathrm{L}$ (VR 7-47). Dentre as manifestações clínicas, todos apresentaram alterações oftalmológicas (sendo 6/10 luxação do cristalino), 8/10 déficits cognitivo, 5/10 eventos tromboembólico prévio e $8 / 10$ alterações ósseas. CONCLUSÃO: A variante foi mais prevalente em pacientes do estado da Bahia, levantando a hipótese de um cluster da doença no estado e um efeito fundador. Observouse um fenótipo grave, controle metabólico inadequado e complicações multi-sistêmicas.

DESCRITORES: Homocistinúria Clássica; Variante p.Trp323Ter. 
ISSN 2447-9071

doi https://doi.org/10.36414/rbmc.v7i17.92

\section{Anais do XVII Congresso Brasileiro de Biomedicina e V Congresso Internacional de Biomedicina}

\section{Prevenção do câncer de colo uterino e câncer de mama em mulheres em condição de vulnerabilidade na região metropolitana de Belém, Pará}

Mayara Nerina Fortes Arthur, Jacqueline Cortinhas Monteiro

Área: Saúde Pública

Instituição de Origem: Centro Universitário de Mineiros - UNIFIMES; Universidade Federal do Triângulo Mineiro - UFTM

INTRODUÇÃO: Para o triênio de 2020-2022 o Instituto Nacional do Câncer, descreve que o câncer de mama (CM) tem maior incidência em todo território brasileiro, estimando-se que 66.280 casos novos, como risco estimado de 61,61 casos novos para 100 mil mulheres. Quanto ao câncer de colo uterino (CCU) encontra-se na terceira posição de incidência, com 16.560 novos casos, tendo um risco estimado de 15,43 casos para 100 mil mulheres. OBJETIVO: realizar de ações de educação em saúde para a prevenção do CCU e CM, visando o esclarecimento acerca de definições, fatores de risco, manifestações clínicas, diagnóstico e prevenção em mulheres em situação de vulnerabilidade social, residentes na região metropolitana da cidade de Belém, Pará. MÉTODOS: Trabalho transversal, visando desenvolver ações educacionais por meio de palestras, distribuição de folhetos, "rodas de bate papo". RESULTADOS: Foi realizado três ações, durante as mesmas observou- se que muitas mulheres tinham resistência ao debate de assuntos considerados íntimos, o desconhecimento sob os temas citados. CONCLUSÃO: Com base dessas ações, pode-se que a falta de informação, leva ao medo fazendo com que muitas mulheres não realizem os exames de prevenção - autoexame das mamas, mamografia e PCCU - e o por consequência haja um aumento de óbitos por estes dois tipos de canceres.

DESCRITORES: Câncer de colo; Educação em Saúde; PCCU. 
ISSN 2447-9071

doi https://doi.org/10.36414/rbmc.v7i17.92

\section{Anais do XVII Congresso Brasileiro de Biomedicina e V Congresso Internacional de Biomedicina}

\section{Relação do tipo sanguíneo " $A$ " na piora do prognóstico de pessoas com Covid-19}

Débora Silva Amorim, Felicson Leonardo Oliveira Lima

Área: Banco de Sangue

Instituição de Origem: Unidade de Ensino Superior de Feira de Santana, Faculdade Nobre de Feira de Santana

INTRODUÇÃO: Estudos tem apontado, que pessoas com o tipo sanguíneo"A"apresentam um maior risco para a aquisição da infecção pelo SARS-CoV-2, com possibilidade de evolução com agravos sintomatológicos, entretanto, pouco se sabe sobre o vínculo que os grupos sanguíneos possuem com os vírus e/ou doenças. OBJETIVO: Descrever a relação entre o tipo sanguíneo"A" com a piora do prognóstico de pacientes com COVID-19. MÉTODOS: Foi realizado um estudo exploratório de caráter quantitativo, fundamentado em dados coletados na plataforma CNN Brasil, bem como, PubMed e SciELO. A elucidação dos dados foi baseada na averiguação de informes de 1.900 pacientes com COVID-19 em estado grave, comparando os dados de 2.300 pessoas que não estavam doentes. RESULTADOS: Possuintes do tipo sanguíneo "A" apresentam um maior risco (45\%) de infectar-se pelo SARS-CoV- 2 e de evoluir para os estágios mais graves, quando comparados às pessoas com outros tipos sanguíneos. Em contrapartida, pacientes com sangue tipo "O" demostraram possuir um risco de $35 \%$ menor de serem infectadas em comparação com os outros tipos sanguíneos. CONCLUSÃO: Os resultados do presente estudo demostram que pessoas com o tipo " $\mathrm{A}$ " são mais suscetíveis para o desenvolvimento da COVID-19, bem como problemas de coagulação, estes, ligados à evolução desfavorável da presente doença, por outro lado, as pessoas com o tipo "O" são menos propensas, o que não descarta a necessidade de medidas preventivas e de etiqueta respiratória para todas os tipos sanguíneos.

DESCRITORES: Tipo Sanguíneo “A”; Covida-19; Prognóstico. 
ISSN 2447-9071

doi https://doi.org/10.36414/rbmc.v7i17.92

\section{Anais do XVII Congresso Brasileiro de Biomedicina e V Congresso Internacional de Biomedicina}

\section{Resistência antimicrobiana para Pseudomonas aeruginosa em úlceras de pressão}

Carolina Braga Borges, Camila Lima Guimarães, Maraiza Oliveira Carrijo, Glauceni de Souza e Silva, Melissa Carvalho Martins de Abreu, Marcelo Costa Araújo, Wellington Francisco Rodrigues, Camila Botelho Miguel

Área: Análises Clínicas

Instituição de Origem: Centro Universitário de Mineiros - UNIFIMES; Universidade Federal do Triângulo Mineiro - UFTM

INTRODUÇÃO: Indivíduos atendidos por programas de atenção domiciliar são um público propenso a desenvolver infecções bacterianas devido à baixa imunidade. Úlceras de Pressão (UP) podem se tornar foco de infecções, cujo tratamento é realizado através do uso de antimicrobianos. OBJETIVO: Verificar o perfil de resistência antimicrobiano para Pseudomonas aeruginosa em UP presentes em indivíduos atendidos por um Programa de Atenção Domiciliar na cidade de Mineiros/GO. MÉTODOS: Foram realizadas a higienização das UP e coletados o material com swab estéril em meio de transporte Stuart. Após isoladas as bactérias, foram identificadas através de testes específicos para cada classe e em seguida foi realizado o antibiograma para verificação do perfil de resistência antimicrobiano. As amostras positivas para Pseudomonas aeruginosa foram computadas e 0 perfil do antibiograma avaliado. RESULTADOS: Foram analisadas 73 amostras positivas para algum micro-organismo e destes, em 27 foram identificadas Pseudomonas aeruginosa (37\%). Dentre os antimicrobianos com maior resistência, os resultados mostraram que $100 \%$ das amostras testadas foram resistentes para Amoxicilina + Ácido Clavulânico e Cefoxitina, 74,1\% para Ampicilina + Sulbactan, 59,3\% para Ceftriaxona, 55,6\% para Imipenem, 51,9\% para Polimixina B e 44,4\% para Meropenem. CONCLUSÃO: Assim, observa-se um perfil de resistência antimicrobiano elevado, o que dificulta a escolha de um antibiótico para tratamento com eficácia.

DESCRITORES: Atenção domiciliar; Pseudomonas aeruginosa; Antibiograma. 
ISSN 2447-9071

doi https://doi.org/10.36414/rbmc.v7i17.92

\section{Anais do XVII Congresso Brasileiro de Biomedicina e V Congresso Internacional de Biomedicina}

\section{Sensibilidade e especificidade do índice de conicidade e da razão cintura-estatura como discriminadores da pressão arterial elevada em idosos}

Saulo Vasconcelos Rocha, Mariana Alves dos Santos, Manuela Alves dos Santos, Clarice Alves dos Santos

Área: Saúde Pública

Instituição de Origem: Universidade Estadual do Sudoeste da Bahia (UESB)

INTRODUÇÃO: Indicadores antropométricos como o Índice de Conicidade (IC) e Razão Cintura-Estatura (RCE) são caracterizados como ferramentas de triagem para avaliação de obesidade central e riscos cardiometabólicos na população idosa. OBJETIVO: Este estudo teve como objetivo selecionar através da sensibilidade e especificidade os melhores pontos de corte para o IC e a RCE como discriminadores de risco para pressão arterial elevada em idosos. MÉTODOS: Estudo transversal realizado com 310 idosos (idade $\geq 60$ anos) participantes do projeto de Monitoramento das Condições de Saúde de Idosos de um Município de Pequeno Porte (MONIDI). Para análise do desempenho do IC e RCE como discriminadores do risco coronariano de pressão arterial elevada em idosos foi utilizada a Receiver Operating Characteristic Curve (ROC), considerando-se sensibilidade e especificidade para melhor ponto de corte. Foi aplicado um intervalo de confiança de 95\%. RESULTADOS: A área total sob a curva ROC entre o IC e a pressão arterial elevada foi de 0,57, IC 95\% $(0,51-0,63)$ e entre a RCE e a pressão arterial elevada foi de 0,58 , IC $95 \%(0,53-0,64)$. Os melhores pontos de corte para discriminar o risco coronariano elevado foram, para o IC e a RCE respectivamente, 1,26 (sensibilidade de $62,5 \%$ e especificidade de $47,1 \%$ ) e 0,58 (sensibilidade de $53,9 \%$ e especificidade de 62,2\%). CONCLUSÃO: Os resultados do presente estudo sugerem que o IC e a RCE discriminam adequadamente a pressão arterial elevada em idosos.

DESCRITORES: Antropometria; Envelhecimento; Hipertensão; Idoso. 
ISSN 2447-9071

doi https://doi.org/10.36414/rbmc.v7i17.92

\section{Anais do XVII Congresso Brasileiro de Biomedicina e V Congresso Internacional de Biomedicina}

\section{Soroprevalencia da imunoglobulina g contra antígenos específicos de plasmodium vivax em indivíduos com malária assintomática}

Gabriela Ribeiro Gomes, Gregório Guilherme Almeida, Ricardo Tostes Gazzinelli, Lis Ribeiro do Valle Antonelli

Área: Docência e Pesquisa

Instituição de Origem: Instituto Rene Rachou - Fiocruz Minas

INTRODUÇÃO: A identificação acurada de indivíduos com infecção assintomática pelo Plasmodium vivax e seu subsequente tratamento podem ser de grande importância no controle da malária em regiões endêmicas. OBJETIVO: Verificar os níveis de anticorpos IgG totais contra antígenos recombinantes do $P$. vivax em indivíduos com infecção assintomática. MÉTODOS: Indivíduos assintomáticos infectados pelo P. vivax foram detectados pela técnica de PCR em tempo real, em região endêmica para a doença. Indivíduos saudáveis com PCR negativa e pacientes sintomáticos com microscopia e PCR positiva foram incluídos como grupos controles. Foram avaliados os níveis de anticorpos através do ensaio imunoenzimático ELISA. RESULTADOS: Foram analisados 105 indivíduos, sendo, 47 assintomáticos, 20 saudáveis e 38 pacientes sintomáticos. Dentre os indivíduos assintomáticos, 78,7\% apresentaram níveis de lgG total contra PvMSP-119 acima do ponto de corte, comparado com $81,5 \%$ dos sintomáticos. Utilizando os antígenos PvAMA166 e PvDBPIIHAP14, 63,8\% e 53,2\% dos assintomáticos apresentaram resultados acima do ponto de corte, respectivamente. Dentre os sintomáticos, $65,7 \%$ e $63,1 \%$ foram positivos para os mesmos antígenos, respectivamente. Quatro indivíduos assintomáticos não apresentaram anticorpos contra nenhum dos três antígenos. CONCLUSÃO: Esses resultados demonstram que a maioria dos indivíduos assintomáticos apresenta produção de anticorpos contra antígenos MSP-119, AMA-166 e DBPIIHAP14.

DESCRITORES: Plasmodium vivax; Malária; Assintomático. 
ISSN 2447-9071

doi https://doi.org/10.36414/rbmc.v7i17.92

\section{Anais do XVII Congresso Brasileiro de Biomedicina e V Congresso Internacional de Biomedicina}

\section{Tendência da mortalidade por câncer do colo do útero no estado da Bahia: 2014 a 2018}

Débora Silva Amorim, Felicson Leonardo Oliveira Lima

Área: Citologia Oncótica

Instituição de Origem: Unidade de Ensino Superior de Feira de Santana, Faculdade Nobre de Feira de Santana

INTRODUÇÃO: O Câncer do Colo do Útero é uma neoplasia maligna, ocasionada pela infecção persistente do Papilomavírus Humano (HPV), principalmente por seus subtipos oncogênicos, em especial o HPV-16 e HPV-18. OBJETIVO: Verificar a tendência da mortalidade por Câncer do Colo do Útero na Bahia entre os anos de 2014 a 2018, evidenciando os óbitos ocorridos nas faixas etárias de 40 a 49 anos. MÉTODOS: Trata-se de um estudo ecológico, com perfil retrospectivo, fundamentado em dados coletados através do Sistema de Informação de Mortalidade (SIM) do Departamento de Informática do Sistema Único de Saúde (DATASUS). Foram analisados dados de óbitos por Câncer do Colo do Útero no estado da Bahia entre 2014 e 2018, nas faixas etárias de 40 a 49 anos. RESULTADOS: Entre os anos de 2014 a 2018 foram registrados um total de 381 óbitos por Câncer do Colo do Útero em mulheres que residiam no estado da Bahia, nas faixas etárias de 40 a 49 anos. De acordo com o SIM/DATASUS os anos que apresentaram maior tendência de mortalidade foram 2015 e 2018, com 83 e 87 óbitos respectivamente. CONCLUSÃO: Os resultados do presente estudo demostraram um crescente número de óbitos ocasionados pelo Câncer do Colo do Útero, na faixa etária de 40 a 49 anos, na Bahia. Portanto, percebe-se a necessidade em conscientizar a população feminina sobre a importância da realização do exame citopatológico, sendo um método útil para o diagnóstico açodado de lesões.

DESCRITORES: Câncer do Colo do Útero; Óbitos; Faixa Etária. 
ISSN 2447-9071

doi https://doi.org/10.36414/rbmc.v7i17.92

\section{Anais do XVII Congresso Brasileiro de Biomedicina e V Congresso Internacional de Biomedicina}

\section{Uso do antígeno prostático específico (psa) na triagem de alterações prostáticas em usuários do sus no VI Distrito de Saúde de Maceió/AL}

Fabíola de Almeida Brito, Lucas dos Santos Ferreira, Mayara Acioli Cedrim, Thaís Raiol Figueredo, Márcia Raquel Cedrim Vieira

Área: Saúde do Homem

Instituição de Origem: Centro Universitário CESMAC, Faculdade Estácio- Fal

INTRODUÇÃO: Dados da Organização Mundial da Saúde (OMS) apontam que o Câncer de próstata é o segundo mais prevalente entre homens, sendo a sexta causa de morte mais frequente nesta população. OBJETIVO: Monitorar os valores de Antígeno Prostático Específico (PSA) em usuários do SUS, atendidos em um laboratório da cidade de Maceió-AL. MÉTODOS: Trata-se de um estudo retrospectivo utilizando-se os registros do laboratório no período compreendido entre outubro de 2019 e agosto de 2020 . Como parâmetros observou-se: a idade e os níveis de PSA livre e total, além da relação entre eles. RESULTADOS: Observou-se um total de 606 registros de pacientes. Dentre estes, 330 com idade acima de 60 anos, enquanto 276 pacientes apresentam idade abaixo de 60 anos. Dos pacientes participantes do estudo apenas 3,52\% $(n=18)$ apresentam idade igual ou inferior a 39 anos. A faixa que compreende idades entre 40 e 59 anos representa 50,58\% ( $n=258$ ), seguida da faixa que inclui pacientes com idade acima de 60 anos, correspondendo à 64,7\% (n=330). CONCLUSÃO: Com a análise detalhada dos dados foi possível verificar a relação entre a idade e as alterações prostáticas, sendo mais prevalente em pacientes com idade superior a 60 anos.

DESCRITORES: Antígeno Prostático Específico (PSA); Alterações na Próstata; Rastreamento; Prevenção; Saúde do Homem. 